\title{
New genomic resources for switchgrass: a BAC library and comparative analysis of homoeologous genomic regions harboring bioenergy traits
}

\author{
Christopher A Saski ${ }^{1}$, Zhigang Li ${ }^{2}$, Frank A Feltus ${ }^{1,2}$ and Hong Luo ${ }^{2 *}$
}

\begin{abstract}
Background: Switchgrass, a C4 species and a warm-season grass native to the prairies of North America, has been targeted for development into an herbaceous biomass fuel crop. Genetic improvement of switchgrass feedstock traits through marker-assisted breeding and biotechnology approaches calls for genomic tools development. Establishment of integrated physical and genetic maps for switchgrass will accelerate mapping of value added traits useful to breeding programs and to isolate important target genes using map based cloning. The reported polyploidy series in switchgrass ranges from diploid $(2 X=18)$ to duodecaploid $(12 X=108)$. Like in other large, repeat-rich plant genomes, this genomic complexity will hinder whole genome sequencing efforts. An extensive physical map providing enough information to resolve the homoeologous genomes would provide the necessary framework for accurate assembly of the switchgrass genome.

Results: A switchgrass BAC library constructed by partial digestion of nuclear DNA with EcoRl contains 147,456 clones covering the effective genome approximately 10 times based on a genome size of 3.2 Gigabases ( 1.6 Gb effective). Restriction digestion and PFGE analysis of 234 randomly chosen BACs indicated that $95 \%$ of the clones contained inserts, ranging from 60 to $180 \mathrm{~kb}$ with an average of $120 \mathrm{~kb}$. Comparative sequence analysis of two homoeologous genomic regions harboring orthologs of the rice OsBR/1 locus, a low-copy gene encoding a putative protein kinase and associated with biomass, revealed that orthologous clones from homoeologous chromosomes can be unambiguously distinguished from each other and correctly assembled to respective fingerprint contigs. Thus, the data obtained not only provide genomic resources for further analysis of switchgrass genome, but also improve efforts for an accurate genome sequencing strategy.

Conclusions: The construction of the first switchgrass BAC library and comparative analysis of homoeologous harboring OsBR/1 orthologs present a glimpse into the switchgrass genome structure and complexity. Data obtained demonstrate the feasibility of using HICF fingerprinting to resolve the homoeologous chromosomes of the two distinct genomes in switchgrass, providing a robust and accurate BAC-based physical platform for this species. The genomic resources and sequence data generated will lay the foundation for deciphering the switchgrass genome and lead the way for an accurate genome sequencing strategy.
\end{abstract}

\section{Background}

The global use of energy crops as renewable fuels and alternative sources of farm income is of great importance to current ecological and economic issues. Switchgrass (Panicum virgatum, L., Poaceae), a warm-season perennial native to the prairies of North America, has been

\footnotetext{
* Correspondence: hluo@clemson.edu

${ }^{2}$ Department of Genetics and Biochemisty, Clemson University, 100 Jordan Hall, Clemson, SC 29634, USA

Full list of author information is available at the end of the article
}

identified by the U.S. Department of Energy (DOE) for development into an herbaceous biomass fuel crop [1,2]. Switchgrass ranges from Quebec to Central America and, like maize, is a $\mathrm{C} 4$ species, fixing carbon by multiple metabolic pathways with high water use efficiency $[3,4]$. Currently, there are breeding programs focusing on high yield, high cellulose content, and low ash characteristics [5-7]. Primarily used for summer forage, hay, and conservation plantings [8], switchgrass is an ideal biomass energy source because of its moderate to high productivity, stand
C Biomed Central

() 2011 Saski et al; licensee BioMed Central Ltd. This is an Open Access article distributed under the terms of the Creative Commons Attribution License (http://creativecommons.org/licenses/by/2.0), which permits unrestricted use, distribution, and reproduction in any medium, provided the original work is properly cited. 
longevity, high moisture and nutrient use efficiency, excellent pest and disease resistance, low cost of production, compatibility with current harvesting and haying equipment, soil restoring properties, erosion control, and adaptability to marginal soils in most agricultural regions in North America.

Given the inherent advantages of utilizing switchgrass as a biofuel feedstock, genetic improvement of switchgrass for more cost-effective biofuel conversion is a possibility that should be pursued. Feedstock traits that can be improved through breeding and biotechnology approaches include enhanced biomass yield, modified lignin production to make sugars in switchgrass more accessible, improved plant biotic and abiotic tolerance, and a long list of new potential uses for primary or co-products. All of these trait enhancements call for genomic tools development. Establishment of integrated physical and genetic maps for switchgrass will make it possible to map value added traits useful to breeding programs and to isolate important target genes using map based cloning.

Improved genetics and agronomics will certainly further enhance energy sustainability and increase biofuel yields from switchgrass. However, realizing the full genetic potential of this species is currently hampered by our lack of knowledge about its evolutionary history, closest relatives, and multiple polyploidy states. In spite of the economic and agricultural importance of switchgrass, few genomic resources exist. There are currently no reports of trait mapping in switchgrass [9], and EST and genomic microsatellite markers are just beginning to be developed [10-14]. The first publicly available switchgrass genetic map possesses only 102 RFLP markers distributed over eight homology groups [15]. A more recent work employing EST-SSR, genomic SSR and EST-STS markers led to the construction of genetic maps of two lowland switchgrass genotypes. Each map coalesced into 18 linkage groups arranged into nine homoeologous pairs [13]. Advances in sequencing and genotyping technology that have been made in the last decade will allow leapfrogging into the latest technology that should enable the application of marker assisted selection techniques such as whole genome selection. These modern breeding methods could dramatically reduce time and cost of cultivar development by reducing the amount of phenotypic analysis that is required especially in early cycles of selection. Availability of an accurate genome sequence will facilitate this vision.

It has been observed that switchgrass cultivars can have different numbers of chromosomes [16]. The reported polyploidy series in switchgrass ranges from diploid (2X $=18)$ to duodecaploid $(12 \mathrm{X}=108)$ [16-21]. To date, all lowland ecotypes examined are tetraploids $(4 \mathrm{x}=36)$, while upland ecotypes are tetraploids, hexaploids, or octaploids [16,20,22,23]. In 1998, DNA content (2C) for several tetraploid plants from lowland cultivars was measured and found to be $3.07 \pm 0.06 \mathrm{pg}$ per nucleus in average [16], so the effective genome size is $\sim 1600 \mathrm{Mb}$ for Alamo derived genotypes. To date, genomic sequencing efforts on other large, repeat-rich, plant genomes such as wheat (Triticum estivum L.), barley (Hordeum vulgare L.), maize (Zea mays L.), and sorghum (Sorghum bicolor L.) have been hindered by genomic complexity resulting in sequence assembly problems [24]. This is even more pronounced in outcrossing plants such as poplar (Populus tremuloides Michaux) [25]. A recent report indicated that sequencing the switchgrass genome to an $8 \times$ coverage using $2 \times 150$ bp of mate pair information with 454 sequencing technology would cost $\sim \$ 1$ million USD [26]. It has also been suggested that with this depth and type of sequencing in hand, retrotransposon families and highly repetitive regions would not be resolved well [27]. It has been suggested that a high quality physical map with enough resolution of homoeologous genomes would ensure assembly and sequencing of a minimum tiling path of large-insert clones, and the physical map would also make it possible to determine haplotypes over extensive regions [26].

Here, we present the first switchgrass BAC library with a glimpse into switchgrass genome structure and complexity as revealed by comparative sequence analysis of two homoeologous BAC assemblies derived from a genomic region that harbors orthologs of the rice OsBRI1 locus, a low-copy gene that encodes a putative protein kinase with a high similarity to $B R I 1$, a brassinosteroid (BR) receptor in Arabidopsis, which has been shown to be associated with plant biomass in rice [28]. Our data support a trend toward autopolyploidy and demonstrate the feasibility of using HICF fingerprinting to resolve the homoeologous chromosomes of the two distinct genomes in switchgrass, providing a robust and accurate BAC-based physical platform for this polyploidy species. These genomic resources and sequence data will lay the foundation for deciphering the switchgrass genome and lead the way for an accurate genome sequencing strategy.

\section{Results}

Switchgrass BAC library construction and characterization A BAC library of $P$. virgatum was constructed by partial digestion of nuclear DNA with EcoRI and contains 147,456 clones stored in 384 plates (384-well). The library covers the effective switchgrass genome approximately 10 times based on a genome size of 3.2 gigabases, and is publicly available via the Clemson University Genomics Institute (http://www.genome.clemson.edu). To estimate insert size and distribution of the switchgrass BAC library, 234 BACs were selected at random and analyzed by NotI digestion and PFGE (see example in Figure 1). Clones that appear to be partially digested were not used in insert size calculation. The results indicated that $95 \%$ of the clones 


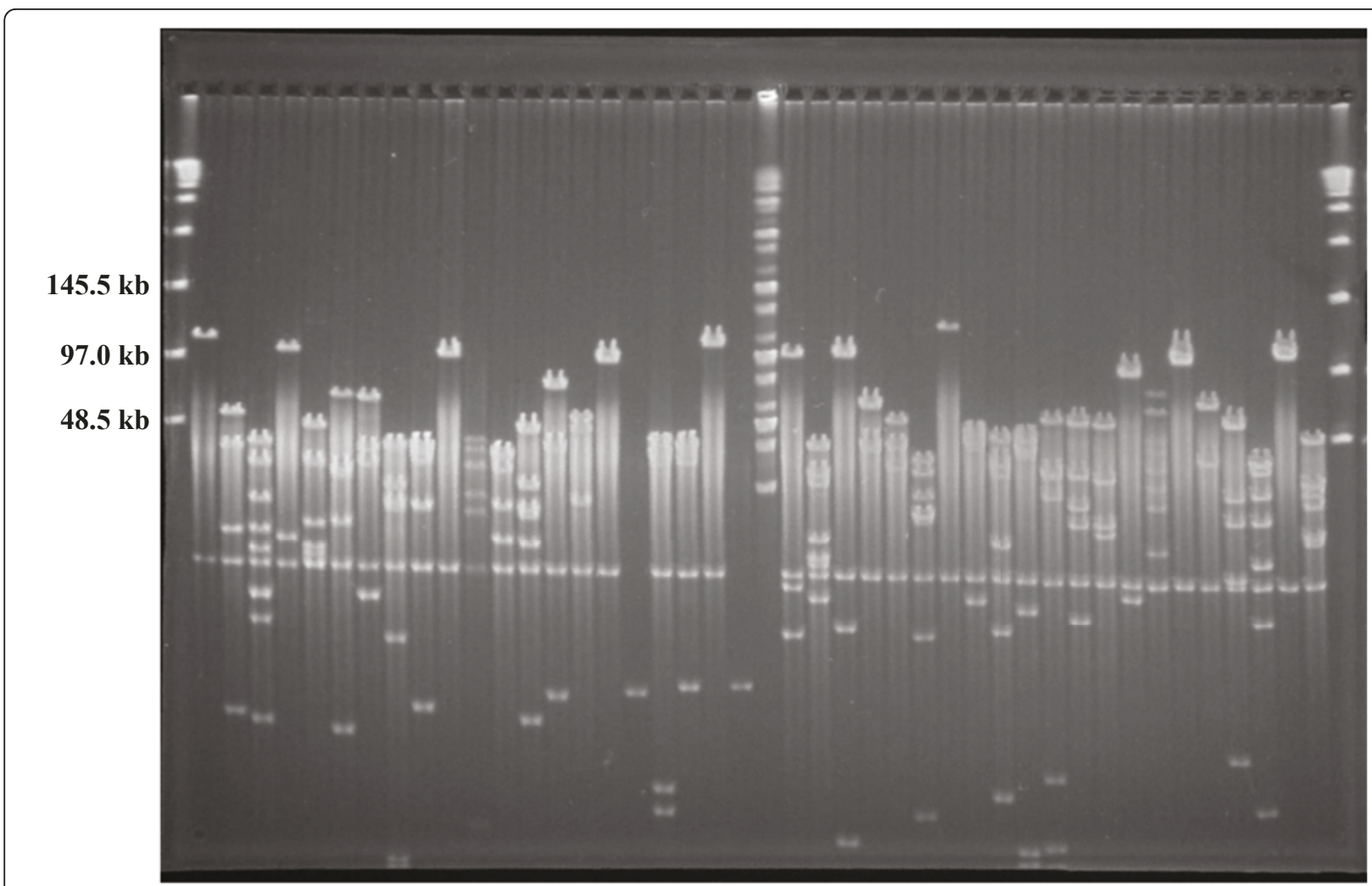

Figure 1 Example insert size distribution of the switchgrass BAC library. Notl digests of BAC DNA isolated from 42 random BAC clones from the switchgrass BAC library. The vector contains two Notl sites that flank the EcoRl cloning sites. The first and last lanes contain the DNA marker Lambda Ladder PFG marker (New England Biolabs, Beverly, MA) and the middle lane contains the DNA marker PFG midrange I (New England Biolabs, Beverly, MA).

contained inserts, and the insert size ranged from 60 to $180 \mathrm{~kb}$ with an average of $120 \mathrm{~kb}$ (Figure 2, Table 1).

\section{Identification and assembly of BACs containing switchgrass orthologs of the rice OsBRI1 gene}

The genotype of the $P$. virgatum we used for BAC library construction is tetraploid. To verify whether or not switchgrass is an autopolyploid, and to examine

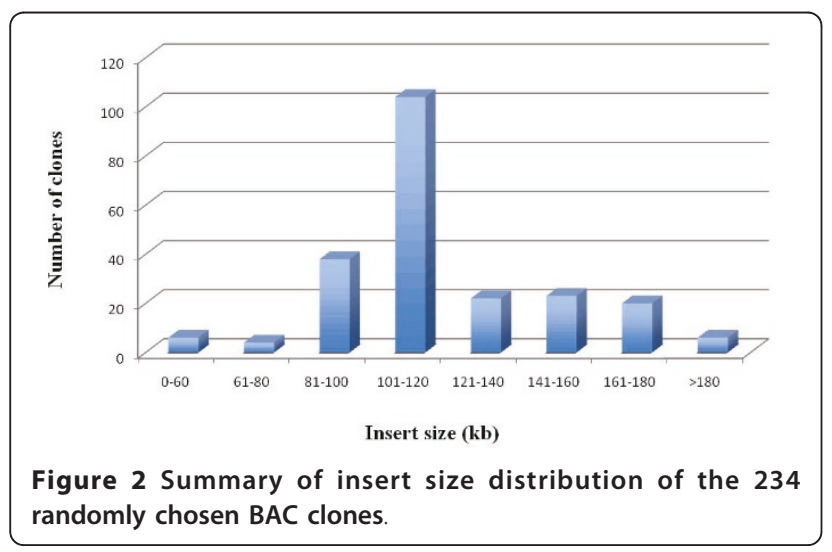

how well the homoeologous BACs can be distinguished and correctly assembled, we set to study individual genes and their surroundings at the genome level by analyzing related $\mathrm{BAC}$ clones in the constructed library. To this end, we screened the BAC library with a rice brassinosteroid insensitive 1 (BRI1) homolog [28], OsBRI1. BRI1 in Arabidopsis and OsBRI1 in rice encode ubiquitously expressed putative receptor kinases. They are both single copy genes and involved in various aspects of plant growth and development. Disruption of BRI1 and OsBRI1 both led to plant dwarfism, greatly impacting plant biomass production [29-31].

We screened 36,872 BAC clones with the single-copy rice gene, OsBRI1 that resulted in 18 positive clones, 6 of which showed strong signal intensity and 12 showed moderate to weak signal strength. To further confirm that the 6 clones showing strong hybridization signals with OsBRI1 probe contain switchgrass orthologs of OsBRI1 gene, two pairs of PCR primers were designed based on sequence of the conserved region of the rice OsBRI1 gene. PCR analysis of the switchgrass OsBRI1 homolog using DNA from the 6 identified BAC clones resulted in two distinct amplification patterns. The clones 
Table 1 Summary of BAC library and HICF fingerprinting of BAC clones

\begin{tabular}{lccccccc}
\hline Library & $\begin{array}{c}\text { Restriction } \\
\text { digest }\end{array}$ & $\begin{array}{c}\text { Cloning } \\
\text { vector }\end{array}$ & $\begin{array}{c}\text { Average insert size } \\
(\mathbf{k b})\end{array}$ & $\begin{array}{c}\# \\
\text { clones }\end{array}$ & $\begin{array}{c}\text { Genome } \\
\text { coverage }\end{array}$ & $\begin{array}{c}\text { Average bands/ } \\
\text { clone }\end{array}$ & $\begin{array}{c}\# \text { of clones } \\
\text { fingerprinted }\end{array}$ \\
\hline$P V_{-} 1^{\mathrm{a}}$ & $E C O R l$ & PCUGIBAC1 & 120 & 147,456 & $10 \times$ & $104^{\mathrm{b}}$ & 18 \\
\hline
\end{tabular}

${ }^{a}$ The library was constructed from $P$. virgatum

${ }^{\mathrm{b}}$ Based on data from the 18 fingerprinted clones

E2 and E3 gave rise to a PCR product with the primer pair of S1, S2, but not with the primer pair of S1, S3. On the contrary, the clones D1, D10, E4 and E5 gave rise to a PCR product with the primer pair of S1, S3, but not with the primer pair of S1, S2 (see example in Figure 3). Sequencing of the two PCR products indicated that they are different OsBRI1 orthologs with high homology (data not shown). Sequencing of representative BAC clones from both groups (see next section) revealed differences in various positions of the S1, S2 and S3 primers between OsBRI1 and its switchgrass counterparts in two BACs (Table 2). It is therefore tempting to speculate that switchgrass OsBRI1 orthologs are single-copy genes, residing in the two homoeologous genomes in the autotetraploid switchgrass, and the two groups of BACs represent DNA fragments from homoeologous regions surrounding OsBRI1 orthologs. To examine this possibility, all 18 identified BACs were subsequently subjected to restriction patterning to determine the extent of shared overlap by High Information Content Fingerprinting (HICF) [32-34]. BAC fingerprinting assembly at $1 \mathrm{e}^{-70}$, tolerance of 4 , resulted in three contigs, of which two corresponded to the two different groups of clones initially revealed by PCR analysis of the OsBRI1 orthologs, i.e., D1, D10, E4 and E5 were in contig 1, whereas E2 and E3 were in contig 2 (Figure 4). A third contig, Contig 3

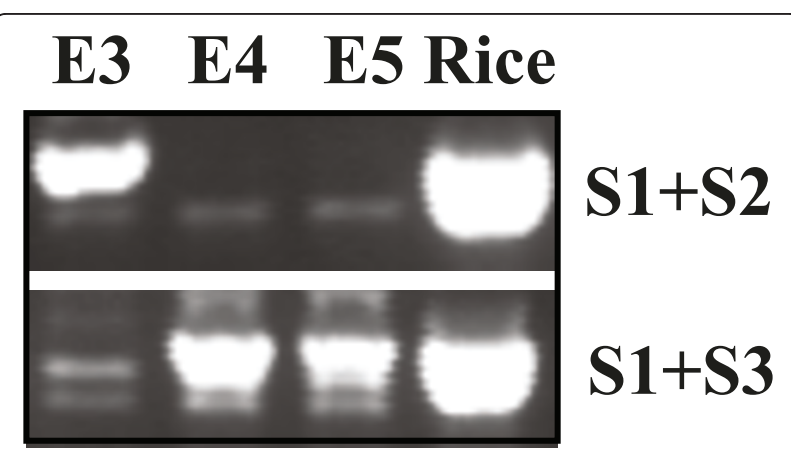

Figure 3 Detection of rice OsBRI1 orthologs in switchgrass. DNA from BAC clones identified by library screening with the rice BR/1 gene (OsBR/1) was used as template for PCR amplification with primers S1, S2 and S3 designed from OsBRI1 sequence (Table 2). Purified PCR products recovered from gel were sequenced to verify their identity. Example of PCR amplification for three orthologous BAC clones, 72H22 (E3), 72K21 (E4) and $92 \mathrm{~J} 12$ (E5) from

homoeologous chromosomes are shown. was composed of 4 BACs identified with moderate hybridization signals that did not produce any positive PCR amplicons when analyzed using primer pairs of S1, S2 and S1, S3 respectively.

\section{BAC sequencing and assembly}

To gain insight into switchgrass OsBRI1 orthologs and their surrounding sequences in the two homoeologous genomes, a consensus BAC from each of the two mapped fingerprint contigs, contig 1 and contig 2 (Figure 4) was sequenced to an $8 \times$ coverage, assembled, and finished according to the bridging shotgun method and the Bermuda standards for finishing. Sequencing of the BAC 48E09 (D10) from the contig 1, and 65J23 (E2) from the contig 2 resulted in a total length of 122,250 bp and 102,051 bp, respectively. Sequence data from the two OsBRI1-containng BAC representatives not only allow for comparative genomic analysis of the switchgrass genome but also provide references to validate assembly of contigs and evaluate switchgrass genome using additional molecular approaches.

Validation of the two switchgrass homoeologous contigs spanning the regions containing the OSBRI1 orthologs

To confirm correct chromosomal locations and genome assignments of the 6 switchgrass BAC clones assembled into two homoeologous contigs spanning the regions containing the OSBRI1 orthologs (Figure 4), twelve pairs of primers were designed based on the sequences of the two BAC clones, 48E09 (D10) and 65J23 (E2), and utilized for PCR with DNAs from the 6 OsBRI1 ortholog-containing BACs (Additional file 1). Presence or absence of PCR amplicons in each of the 6 BACs mapped to the two contigs should confirm correct contig assembly, and therefore the genome and homoeologous chromosomal assignment. As demonstrated in Figure 5 and summarized in Table 3, the presence or absence of PCR amplicons for each of the 6 BACs match the patterns as predicted from the physical maps, thus supporting contig assembly obtained by BAC fingerprinting (Figure 4). These initial data indicate the feasibility of using HICF fingerprinting to resolve the homoeologous chromosomes of the two distinct genomes in switchgrass, providing a robust and accurate BAC-based physical platform for this polyploidy species. 
Table 2 Comparison of primer sequences between OsBRI1 and its switchgrass homologs ${ }^{\mathrm{a}}$

\begin{tabular}{|c|c|c|c|}
\hline Primer & S1 & S2 & S3 \\
\hline Rice & TGGAGACCATTGGCAAGATC & GCGATITTCAAATGCTCCAG & TCCAAGCACGCACAGGCG \\
\hline BAC 48E09 (D10) ${ }^{b}$ & TGGAGACTATTGGCAAGATC & GCAACCTTCAAGTGCTCCAGG & 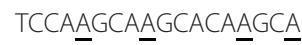 \\
\hline BAC 65J23 (E2) ${ }^{b}$ & TGGAGACCATTGGCAAGATC & GCAACCTTCAGGTGCTCCAGG & TCCAGGCAAGCACAAGCA \\
\hline
\end{tabular}

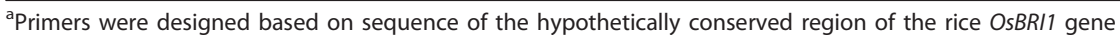

${ }^{b}$ The corresponding sequences of the switchgrass homologs of the OsBRI1 gene in two homoeologous BACs are also listed. The different nucleotides are underlined.

\section{Assessment of the tetraploid switchgrass genome by Southern analysis}

Sequencing data from the two switchgrass OsBRI1 ortholog-containing BACs provide information about restriction sites surrounding the OsBRI1 orthologs. To further confirm that orthologs of the OSBRI1 are indeed singlecopy genes in switchgrass, we conducted southern analysis of switchgrass genomic DNA using the rice OsBRI1 gene as probe. DNA was digested with three enzymes, BamHI, PstI and XhoI, and rice genomic DNA was used as positive control. Hybridization of OsBRI1 to BamHIor PstI-digested rice genomic DNA both resulted in one single band of expected size as predicted from rice genomic DNA sequence (Figure 6, Table 4). When XhoIdigested rice genomic DNA was probed by OsBRI1, two bands of expected sizes $(\sim 1.2 \mathrm{~kb}$ and $5.4 \mathrm{~kb})$ were revealed (Figure 6, Table 4). An additional band of $>6 \mathrm{~kb}$ was also observed most probably due to incomplete digestion of genomic DNA (Figure 6). Similarly, switchgrass genomic DNA digested with various restriction enzymes led to the same patterns as predicted from the sequences of the two BAC clones, and no additional hybridization signals were detected (Figure 6, Table 4). Hybridization of BamHI-digested genomic DNA with heterologous probe, OsBRI1 revealed three bands of $\sim 2.3$ $\mathrm{kb}, 7.3 \mathrm{~kb}$, and $7.8 \mathrm{~kb}$ as well as an additional band of $>3$

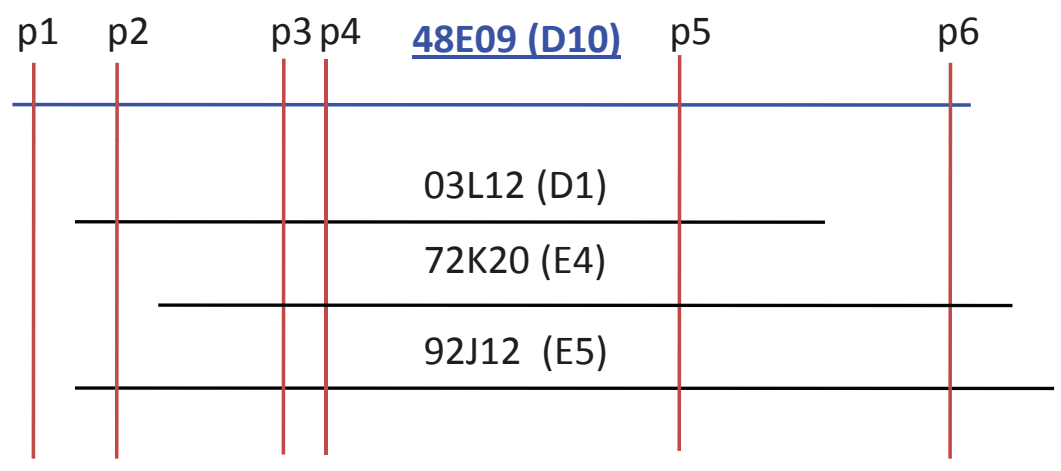

Contig 1

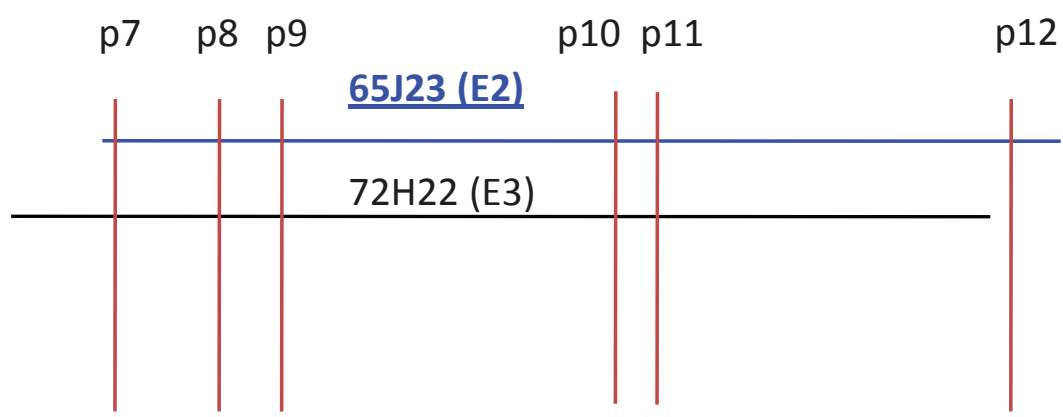

Contig 2

Figure 4 Physical map of the switchgrass genome region containing OsBRI1 orthologs. Contig assembly of the 6 OsBR/1 orthologcontaining BACs using HICF fingerprinting with a cutoff of $\mathrm{e}^{-30}$ and a tolerance of 4 resulted in an assembly with 2 contigs: Contig 1 with 4 BACs, Contig 2 with 2 BACs. The two contigs represent two homoeologous genomes in switchgrass. The locations of the 12 predicted PCR products ( $\mathrm{p} 1$ to $\mathrm{p12}$ ) using the 12 pairs of primers (Additional file 1) designed based on sequence data from the two BAC clones, 48E09 (D10) and $65 J 23$ (E2) are indicated on the map. 


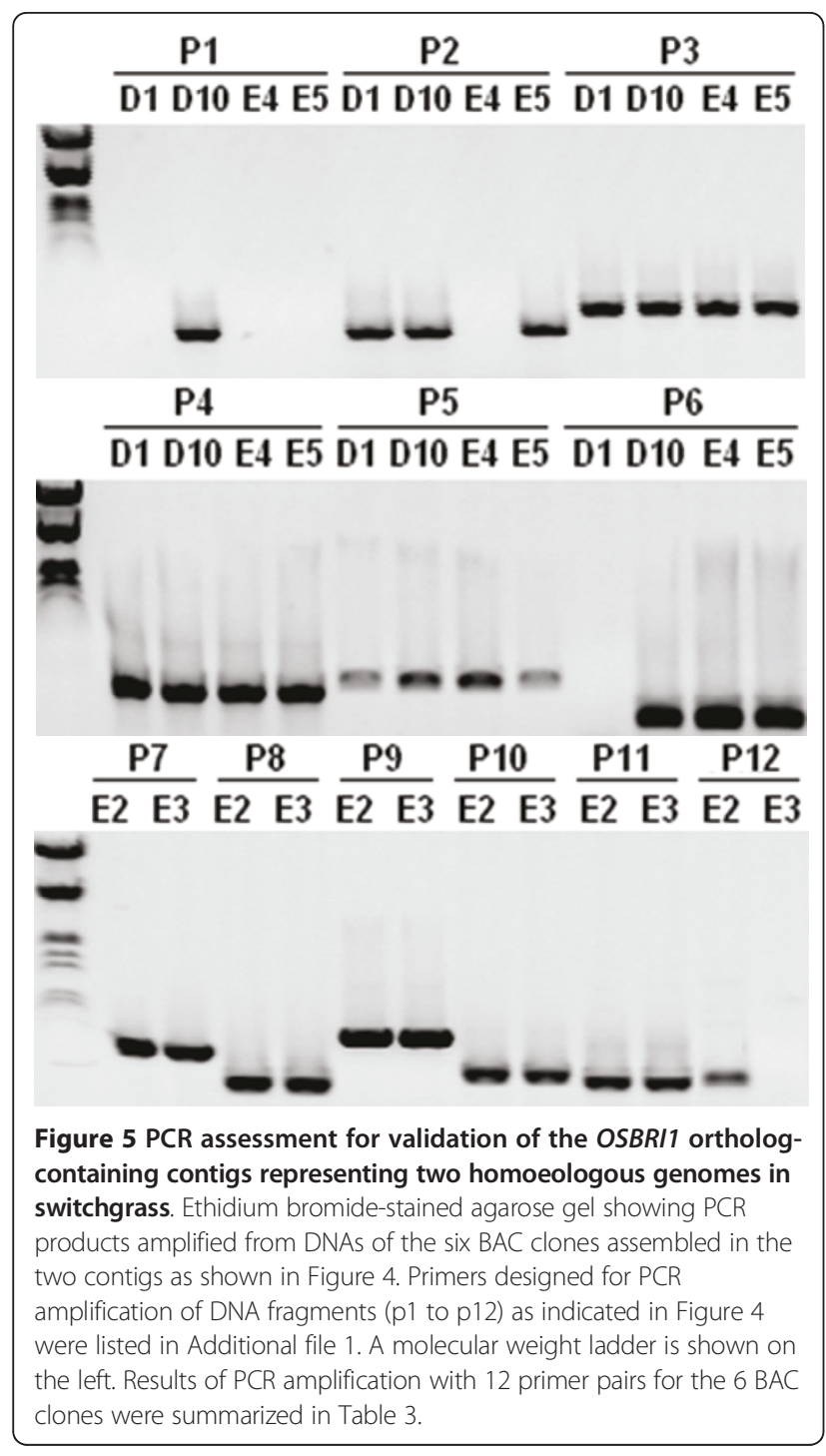

Table 3 Summary of PCR assessment for contig validation (see Figure 5$)^{a}$

\begin{tabular}{lllllll}
\hline Primer Pairs & D1 & D10 & E2 & E3 & E4 & E5 \\
\hline p1 & - & + & - & - & - & - \\
p2 & + & + & - & - & - & + \\
p3 & + & + & - & - & + & + \\
p4 & + & + & - & - & + & + \\
p5 & + & + & - & - & + & + \\
p6 & - & + & - & - & + & + \\
p7 & - & - & + & + & - & - \\
p8 & - & - & + & + & - & - \\
p9 & - & - & + & + & - & - \\
p10 & - & - & + & + & - & - \\
p11 & - & - & + & + & - & - \\
p12 & - & - & + & - & - & - \\
\hline a“+" denotes PCR positive, whereas "_-" denotes PCR negative &
\end{tabular}

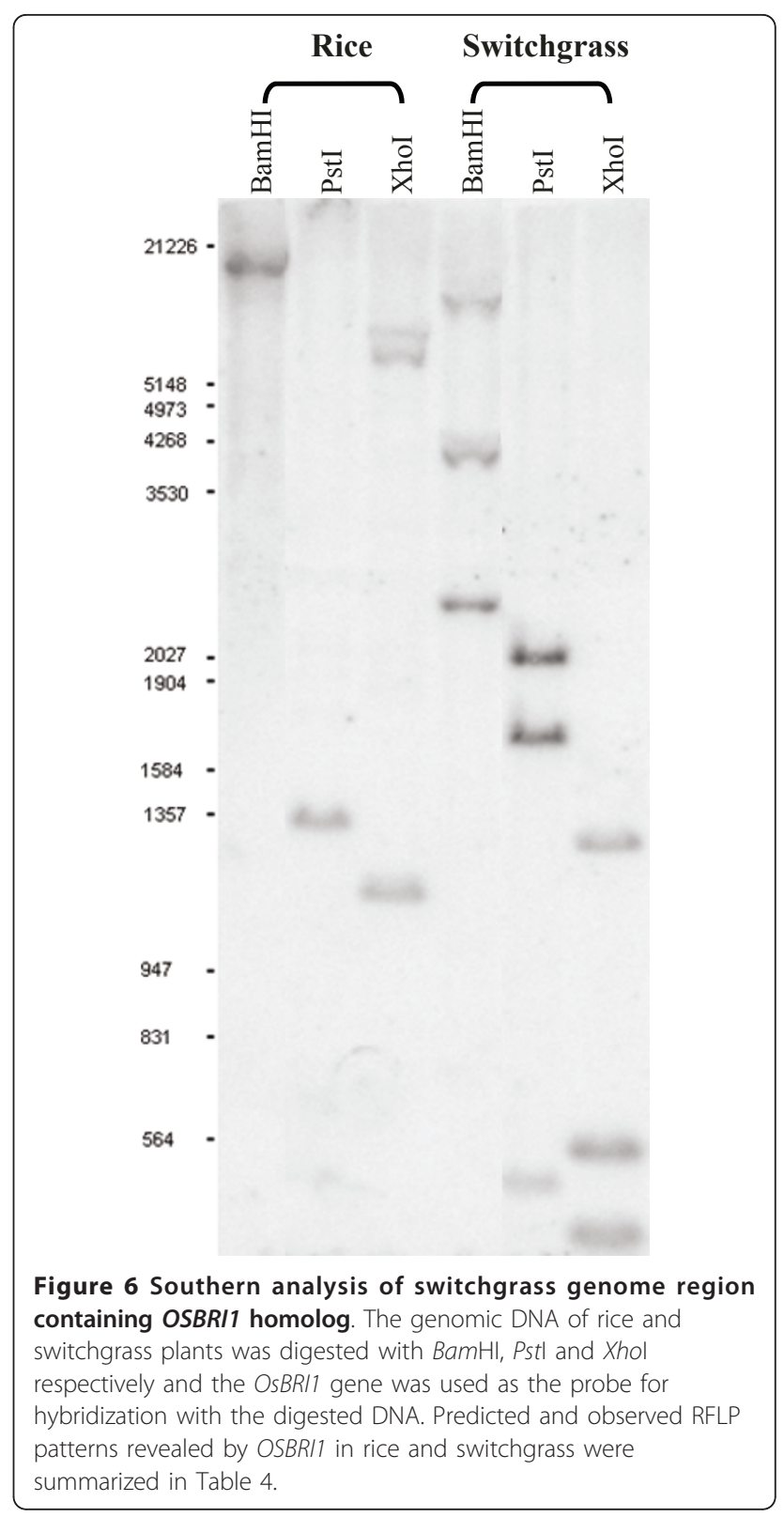

$\mathrm{kb}(\sim 4.0 \mathrm{~kb})$, in agreement with the pattern predicted from the sequences surrounding the OsBRI1 orthologs in the two BAC clones, 48E09 (D10) and 65J23 (E2) (Figure 6, Table 4). Hybridization of PstI-digested genomic DNA with heterologous probe, OsBRI1 revealed three bands of $\sim 2.0 \mathrm{~kb}, 1.7 \mathrm{~kb}$ and $0.5 \mathrm{~kb}$ as expected (Figure 6, Table 4 ), one additional predicted DNA fragment of $88 \mathrm{bp}$ was not observed in this blot because it had run out of the gel during electrophoresis, which was confirmed in a separate Southern hybridization experiment (data not shown). In the case of DNA digested by XhoI, Southern hybridization resulted in three bands of predicted sizes of $\sim 1.3 \mathrm{~kb}, 0.6 \mathrm{~kb}$ and $0.45 \mathrm{~kb}$ (Figure 6, Table 4). The fourth band of $382 \mathrm{bp}$ had run out of the gel during 
Table 4 Predicted and observed RFLP patterns revealed by OSBRI1 in rice and switchgrass (see Figure 6)

\begin{tabular}{|c|c|c|c|c|c|c|c|}
\hline \multirow[t]{2}{*}{ Clone (bp) } & \multirow[t]{2}{*}{ Probe position (bp) } & \multicolumn{2}{|c|}{ BamHI } & \multicolumn{2}{|c|}{ Pstl } & \multicolumn{2}{|c|}{ Xhol } \\
\hline & & Expected (bp) & Actual (bp) & Expected (bp) & Actual (bp) & Expected (bp) & Actual (bp) \\
\hline \multirow[t]{4}{*}{ Switchgrass BAC 48E09 (122250) } & 73868 & 2339 & + & 523 & + & 382 & * \\
\hline & - & 7758 & + & 1673 & + & 446 & + \\
\hline & 75557 & & & & & 589 & + \\
\hline & & & & & & 1308 & + \\
\hline \multirow[t]{4}{*}{ Switchgrass BAC 65J23 (102051) } & 98980 & 7304 & + & 88 & * & 382 & $*$ \\
\hline & - & $>3000$ & $\sim 4000$ & 2023 & + & 446 & + \\
\hline & 100669 & & & & & 589 & + \\
\hline & & & & & & 1308 & + \\
\hline \multirow[t]{3}{*}{ Rice PAC AP003453 (151100) } & 66842 & 10590 & + & 94 & * & 1162 & + \\
\hline & - & & & 304 & * & 5438 & + \\
\hline & 68522 & & & 1367 & + & & \\
\hline
\end{tabular}

*DNA fragments smaller than $400 \mathrm{bp}$ that have run out of gel during electrophoresis

electrophoresis, which was confirmed in a separate Southern hybridization experiment (data not shown). Thus, Southern analysis results strongly suggest that the switchgrass OsBRI1 orthologs exist as single-copy genetic loci, residing in two homoeologous genomes, and that the tetraploid switchgrass is autopolyploid.

\section{Homoeology and extent of fractionation between switchgrass BACs}

The two switchgrass BACs sequenced in this study were identified based upon their hybridization to the same OsBRI1 probe and position in different BAC fingerprint contigs (Figure 4). Those experiments do not provide sequence level evidence that these two BACs are indeed homoeologous (polyploidy derived paralogy) and are derived from two ancestral genomes. The BAC to BAC alignment can be visualized in Figure $7 \mathrm{~A}$ and $7 \mathrm{~B}$ as a dot plot or percent identity plot, respectively. Using all 35 BLASTN [35] alignments greater than $50 \mathrm{bp}$ in length, 18,189 nucleotides overlap between the two BACS with an average percent identity of $94 \%$. Both switchgrass BACs map to the same orthologous region in rice (see "Methods") suggesting that they came from a common ancestral position (Figure 7C). In addition, the repeat density for these two BACs is highly similar $(48 \mathrm{E} 09=25.9 \% ; 65 \mathrm{~J} 23=25.4 \%$; Additional file 2$)$ also suggesting that they come from similar genomic regions.

\section{Discussion}

A critical tool for the genomic enablement of any plant species with a large, complex genome is the availability of a deep-coverage, large-insert (BAC) library that can serve as the centrepiece for the generation and integration of genome-level information. BAC libraries serve as the platform for physical mapping, positional cloning, integration of genetic maps, comparative studies, and whole-genome sequencing. We constructed the first switchgrass BAC library consisting of 147,456 clones with an average insert size of $120 \mathrm{~kb}$ using genomic DNA from a lowland ecotype, Alamo derived genotype that has been demonstrated to be superior in biomass production (Wu, personal communication). The switchgrass BAC library totals $10 \times$ coverage of the total nuclear content of this tetraploid switchgrass genotype and $5 \times$ coverage of each of the two genomes.

Polyploids are common in seed plants with the majority of them being allopolyploids. Polyploidy plays an important role in plant genome evolution [36-38]. It has been suggested that the tetraploid switchgrass lowland ecotypes behave as an autopolyploid with complete or near complete disomic inheritance and specific bivalent pairing of chromosomes in groups of four at meiosis [15]. Our data using two sequenced BAC clones suspected to reside on homoeologous genomes, support a trend toward autopolyploidy and the feasibility of resolving the homoeologous genomes in switchgrass using high information content fingerprinting. Saini et al. [39] demonstrated this when the polyploidy nature of Glycine max was assessed by BAC-based fingerprinting, integration of genetic markers, and whole-genome/BAC-end sequence. In soybean, $5-10 \%$ sequence divergence is necessary to separate the homoeologs by HICF fingerprinting [39]. This group used BAC-end sequences from three minimum tile paths to examine the extent of polyploidy-like regions within contigs, and the extent of correlation between the polyploidy-like regions inferred from fingerprinting and the polyploid-like sequences inferred from whole genome shotgun sequence matches [39]. The result improved whole genome sequence contig and scaffold building methods by sequence assessment and physical location. In order to fully understand the origins of the polyploid switchgrass, whole genome sequencing of related taxa and fluorescent in situ hybridization techniques should be used. 


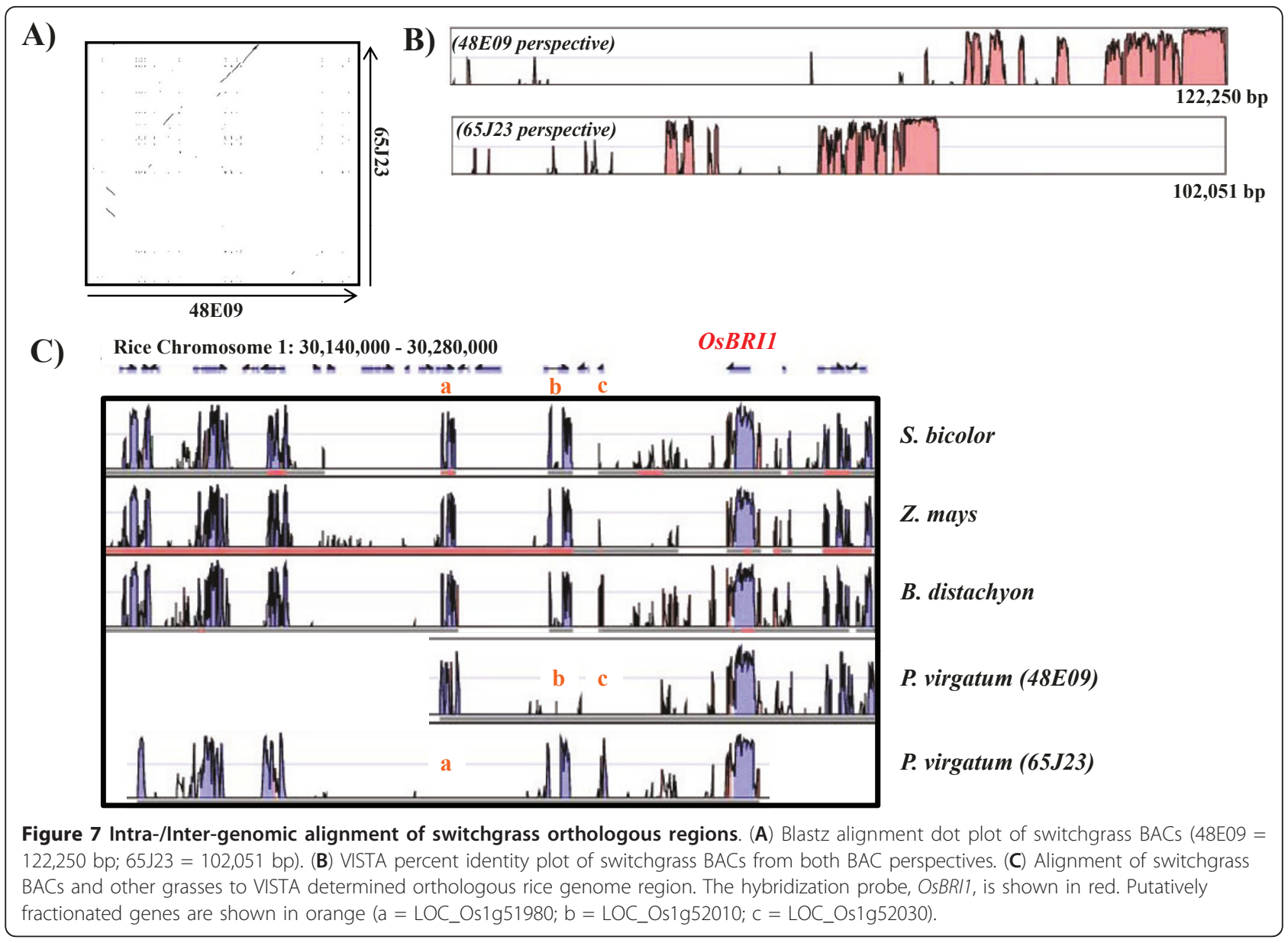

In an effort to assess the possibility of BAC-based physical mapping in polyploidy plant species, Luo et al. [24] assembled contigs of fingerprinted clones in an in silico merged BAC library composed of single-chromosome libraries of two wheat homoeologous chromosome arms, 3AS and 3DS, and complete chromosome 3B. An average of $97.78 \%$ or more clones from a single chromosome arm was achieved, indicating a very high fidelity of contig assembly and the negligibly low level of incorporation of clones from homoeologous chromosome arms into a contig during contig assembly. This result strongly suggests the feasibility of contig construction and physical mapping using global BAC libraries in polyploidy species.

In the current project, we identified 18 clones positive for the OsBR11 homologue by DNA hybridization to the BAC filters. Using HICF, we assembled a BAC clone based physical map of the rice homologue OsBRI1 genomic region in switchgrass and sequenced a consensus BAC from each of the homoeologous contigs for comparative analysis. Of the 18 positive clones, 6 and 12 showed strong and moderate signal intensity, respectively. Upon further analysis of the homoeologous contigs, both switchgrass
BACs map to the same orthologous region in rice suggesting that they came from a common ancestral position. The degree of intragenomic alignment and preservation of gene order relative to all the four grass genomes suggest that the $2 \mathrm{BACs}$ are homoeologous yet have undergone significant fractionation. The degree of fractionation can be qualitatively seen in the alignment of orthologous regions in rice and three additional grasses (Figure 7C). For example, it appears that the sub-genome from which 48E09 (D10) was derived has lost at least two rice genes (LOC_Os1g52010, LOC_Os1g52030) whereas these genes were maintained in the genome from which 65J23 (E2) was derived yet this genome has lost LOC_Os1g51980. These comparative genomic data, degree of sequence divergence, and physical map evidence suggest that the two switchgrass genomes are similar enough to discover homoeologous segments yet divergent enough to make it difficult to select indistinguishable BACs from a BAC library.

To our knowledge, this is the very first report using one gene, OsBRI1 to comprehensively characterize switchgrass genome organization from various aspects demonstrating the feasibility of using HICF to resolve the homoeologous 
chromosomes of the two distinct genomes in this species. Next step would be to extend the analysis using multiple loci covering large genomic regions to further validate the data presented in this study.

BAC-based whole genome physical mapping has recently evolved into the second generation arena and advancement in resolution (i.e., single nucleotide resolution vs. restriction patterning) suggests more robust contig builds. For example, van Oeveren et al. studied the feasibility of using a next-generation sequencing-based strategy, the whole-genome profiling (WGP) for physical mapping [40]. De novo contigs assembly by WGP technology in Arabidopsis thaliana ecotype Columbia resulted in high quality physical map, which was confirmed using the Columbia reference sequence. The application and simulation of this technology in other plant genomes seem to suggest its scalability to complex genomes [40]. Although it remains unclear if next generation physical mapping can resolve homoeologous genomic segments, high-throughput next-generation sequencing-based technologies could potentially lead to more robust solutions towards highly reliable physical map construction, therefore worth exploring. In either case, a heuristic BAC by BAC sequencing approach from a minimum tiling path of the switchgrass genome should work.

\section{Conclusions}

We have constructed a large insert BAC library from a tetraploid switchgrass genotype that contains about 10 genome equivalents with an average insert size of $120 \mathrm{~kb}$. The feasibility of contigs assembly, and eventually physical map construction from fingerprinted BAC clones in a polyploid species was studied. Results from comparative analysis of BACs containing orthologs of the rice OsBRI1 locus demonstrated that orthologous clones from homoeologous chromosomes can be unambiguously distinguished from each other, and correctly assembled to respective contigs. Thus, the data obtained from this research not only provide genomic resources and sequence data for further analysis of switchgrass genome, but also lead the way for an accurate genome sequencing strategy.

\section{Methods}

\section{Plant material}

The Alamo derived tetraploid switchgrass genotype, SL93 2001-1, kindly provided by Dr. Yanqi Wu (Oklahoma State University, Stillwater, OK, USA) was grown and maintained in the greenhouse at Clemson University.

\section{BAC library construction and characterization}

The plants were kept in dark conditions 24 hours prior to harvesting. Approximately 50 grams of young, expanding leaf tissues were harvested and immediately flash frozen in liquid nitrogen prior to nuclei preparation. Nuclei purification and embedding, EcoRI partial restriction enzyme digestion of DNA, as well as the preparation of high molecular weight DNA fragments were conducted following Luo and Wing [41]. Preparation of the EcoRI cloningready single copy pIndigoBAC536 vector from the high copy pCUGIBAC1 plasmid was performed according to Luo et al. [42]. The size-selected high molecular fragments were ligated to vector and transformed into $E$. coli strain DH10B (Invitrogen, Carlsbad, CA, USA). White recombinant colonies were selected on LB plates containing chloramphenicol, X-Gal, IPTG, and picked robotically using the Genetix Q-bot (Genetix, UK). Recombinant clones were transferred into individual wells of 480, 384-well microtiter plates, grown and then stored at $-80^{\circ} \mathrm{C}$. The BAC library was gridded onto $10,11.25 \times 22.25 \mathrm{~cm}$ filters in high density, double spots $(18,432$ clones represented per filter) and $4 \times 4$ patterns. To characterize the BAC inserts, BAC DNA was prepared according to standard alkaline lysis conditions in a 96-well format, digested with NotI, and separated by pulsed field gel electrophoresis (PFGE) on a $1 \%$ agarose gel with the following conditions: 5-15 sec linear ramp time, $6 \mathrm{~V} / \mathrm{cm}, 14^{\circ} \mathrm{C}$ in $0.5 \times \mathrm{TBE}$ buffer for 15 hours and stained with ethidium bromide.

\section{PCR analysis of BAC clones}

PCR analysis was conducted to analyze BAC clones. The primers used were listed in Table 2 and Additional file 1. The reaction mixtures ( $25 \mu$ l total volume) consisted of $50 \mathrm{mM} \mathrm{KCl,} 10 \mathrm{mM}$ Tris- $\mathrm{HCl}$ (pH 8.8), $1.5 \mathrm{mM} \mathrm{MgCl}_{2}$, $0.1 \%(w / v)$ Triton X-100, $200 \mu \mathrm{M}$ each of dATP, dCTP, dGTP, and dTTP, $0.5 \mu \mathrm{M}$ of each primer, $0.2 \mu \mathrm{g}$ of template DNA, and 1 unit of Taq DNA polymerase (Promega, Madison, WI, USA). Amplification was performed in a Bio-Rad MJ mini gradient thermal cycler (Hercules, CA, USA) programmed for 25 cycles of $1 \mathrm{~min}$ at $94^{\circ} \mathrm{C}$ (denaturation), $2 \mathrm{~min}$ at $55^{\circ} \mathrm{C}$ (hybridization), $3 \mathrm{~min}$ at $72^{\circ} \mathrm{C}$ (elongation) and a final elongation step at $72^{\circ} \mathrm{C}$ for $10 \mathrm{~min}$. PCR products were separated in a $0.8 \%(\mathrm{w} / \mathrm{v})$ agarose gel and detected by staining with ethidium bromide.

\section{Southern analysis of genomic DNA}

Plant genomic DNA was isolated from about 300 to $500 \mathrm{mg}$ young leaves using the cetyltrimethyl ammonium bromide (CTAB) method, essentially as described by Luo et al. [43]. Ten micrograms of DNA were digested with BamHI, PstI and XhoI after the supplier's instruction (New England Biolabs, Beverly, MA, USA). Digested DNA was fractionated through a $0.7 \%(\mathrm{w} / \mathrm{v})$ agarose gel and blotted on to a Hybond- ${ }^{+}$filter (GE Healthcare Bio-Sciences Corp., Piscataway, NJ, USA). The 622 bp fragment of OsBRI1 gene amplified from rice genomic 
DNA with primers, S1 and S2 as described above in Table 2 were used as probe. Probe was labelled with the $\left[\alpha-{ }^{32} \mathrm{P}\right] \mathrm{dCTP}$ using Prime-It II Random Primer Labeling Kit (Stratagene, La Jolla, CA, USA). DNA blot was probed in Church buffer at $65^{\circ} \mathrm{C}$ and exposed on phosphor screens at RT overnight and scanned using Typhoon 9400 (GE Healthcare Bio-Sciences Corp., Piscataway, NJ, USA).

\section{Identification of switchgrass BACs containing OsBRI1 homologue}

The switchgrass BAC library was screened to identify OsBRI1 ortholog-containing clones following the procedure described previously [44]. Briefly, approximately $25 \mathrm{ng}$ of the OsBRI1 PCR amplicon was radiolabelled with ${ }^{32} \mathrm{P}$-dATP using the DECAprime ${ }^{\mathrm{TM}}$ random priming DNA labelling kit (Ambion, Inc). Labelled probe was denatured and added against the A and B filters of the switchgrass BAC library. Hybridization was performed at $60^{\circ} \mathrm{C}$ overnight. Filters were washed with $1 \times \mathrm{SSC}, 0.1 \% \mathrm{SDS}$ at $60^{\circ} \mathrm{C}$ for 30 minutes for 5 times and exposed to phosphor screens, and the images were recorded by a Typhoon 9400 Imager (GE Healthcare Bio-Sciences Corp., Piscataway, NJ, USA). The addresses of the positively hybridized BAC clones were manually scored.

\section{Physical map of the OsBRI1 orthologs region in switchgrass homoeologues}

We performed HICF on the 18 strong and moderate positively identified BAC clones and experimented with a range of assembly parameters in FPC to identify the most commensurate build. The parameters ranged from a cutoff of $\mathrm{e}^{-30}$, to $\mathrm{e}^{-70}$, and a tolerance of 4 . The first assembly at $1 \mathrm{e}^{-70}$, tolerance of 4 resulted in 3 contigs: Contig 1 with 3 BACs, Contig 2 with 2 BACs, and Contig 3 with 3 BACs, and 10 singletons. The FPC assembly using a cutoff of $\mathrm{e}^{-30}$ and a tolerance of 4 resulted in a similar assembly with 3 contigs: Contig 1 with 4 BACs, Contig 2 with 2 BACs, and Contig 3 with 4 BACs, and 8 singletons. It is likely that the BACs not assembling into a respective contig is due to a small amount of overlap, stringent assembly conditions, or non-specific identification during DNA hybridization.

\section{Small-insert library production and sequencing of homoeologues}

Small-insert DNA fragments were generated by hydroshearing BAC DNA isolated as a maxi-prep from the BAC clone. Fragments between 3 and $5 \mathrm{~kb}$ were size selected by gel electrophoresis, end-repaired, cloned into the high copy plasmid based cloning vector pBlueskriptIIKSII+, and then electroporated into E. coli DH10B cells. Transformants were selected on LB plates containing carbenicillin, X-Gal and IPTG. White recombinant colonies were picked robotically using the Genetix Q-bot and stored as individual clones in Genetix 96-well microtiter plates as glycerol stocks at $-80^{\circ} \mathrm{C}$. Sub-clones were sequenced with the universal priming sites on the vector in both the forward and reverse directions and sequence data collected on an ABI 3730xl DNA Analyzer. Sequence data was collected to an $8 \times$ sequence coverage.

\section{Inter- and intra-genome comparisons}

Switchgrass BACs were aligned to each other using either blastz at the Pipmaker [45] server (http://pipmaker.bx.psu.edu/pipmaker/) or mVISTA [46] server (http://genome.lbl.gov/vista/) using the LAGAN [47] algorithm. The orthologous region of each switchgrass BAC in Oryza sativa (v5.0) was determined using the GenomeVISTA server (http://genome.lbl.gov/vista/). These overlapping orthologous regions were then compared with the VISTA pre-computed orthologous region for Zea mays (v.3), Sorghum bicolor (v.1.0) and Brachypodium distachyon. Switchgrass repeat component was determined using the Censor $[35,48]$ server (http://www.girinst.org/censor/) and Poaceae repeat libraries.

\section{Additional material}

Additional file 1: Primers designed for use in PCR analyses presented in Figure 5 to verify and validate the contig assembly. Additional file 2: Repeat density of the two BACs, $48 E 09$ (D10) and 65J23 (E2).

\section{Acknowledgements}

We thank Dr. Yanqi Wu (Oklahoma State University, Stillwater, OK, USA) for providing switchgrass line, SL93 2001-1 used in current research. This work was based upon research supported by a grant from the USDA National Institute of Food and Agriculture, under project number SC-1700315 to HL and in part by the Biotechnology Risk Assessment Program Competitive Grants 2007-33522-18489 and 2010-33522-21656 from the USDA National Institute of Food and Agriculture to $\mathrm{HL}$. This is technical contribution no. 5893 of the Clemson University Experiment Station.

\section{Author details}

${ }^{1}$ Clemson University Genomics Institute, Clemson University, Biosystems Research Complex, 51 New Cherry Street, Clemson, SC 29634, USA.

${ }^{2}$ Department of Genetics and Biochemisty, Clemson University, 100 Jordan Hall, Clemson, SC 29634, USA.

\section{Authors' contributions}

CAS constructed and screened the library, conducted HICF physical mapping and BAC sequencing. ZL conducted PCR analysis of BAC clones and Southern analysis. FAF conducted comparative genomic analysis of the OsBR/1 ortholog-containing BACs. CAS and $\mathrm{HL}$ drafted the manuscript. $\mathrm{HL}$ conceived, initiated and supervised the project. All authors read and approved the final manuscript.

Received: 9 February 2011 Accepted: 18 July 2011

Published: 18 July 2011 


\section{References}

1. Vogel KP: Energy production from forages (or American agriculture-back to the future). J Soil Water Conserv 1996, 51:137-139.

2. Vogel KP: Switchgrass. In Warm-Season (C4) Grasses. Edited by: Moser LE, Burson BL, Sollenberger LE. American Society of Agronomy; 2004:561-588.

3. Moss DN, Krenzer EG, Brun WA: Carbon dioxide compensation points in related plant species. Science 1969, 164:187-188.

4. Koshi PT, Stubbendieck J, Eck HV, McCully WG: Switchgrasses: Forage yield, forage quality and water-use efficiency. J Range Manage 1982, 35:623-627.

5. Vogel KP: Improving warm-season grasses using selection, breeding, and biotechnology. In Crop Science Special Publication No. 30: Native warmseason grasses: Research trends and issues. Edited by: Moore KJ, Anderson B. Crop Science Society of America and American Society of Agronomy, Madison, Wl; 2000:83-106.

6. McLaughlin SB, Kszos LA: Development of switchgrass (Panicum virgatum) as a bioenergy feedstock in the United States. Biomass Bioenerg 2005, 28:515-535, (2005)

7. Mitchell Rob, Kenneth P Vogel, Sarath Gautam: Managing and enhancing switchgrass as a bioenergy feedstock. Biofuels, Bioprod Bioref 2008, 2:530-539

8. Moser LE, Vogel KP: Switchgrass, big bluestem, and indiangrass. In Forages: An introduction to grassland agriculture. Edited by: Barnes RF et al. lowa State Univ Press, Ames, IA; 1995:409-420, (1995).

9. Bouton $\mathrm{JH}$ : Molecular breeding of switchgrass for use as a biofuel crop. Curr Opin Genet Dev 2007, 17:553-558

10. Tobias CM, Twigg P, Hayden DM, Vogel KP, Michell RM, Lazo GR, Chow EK, Sarath G: Analysis of expressed sequence tags and the identification of associated short tandem repeats in switchgrass. Theor Appl Genet 2005, 111:956-964.

11. Tobias CM, Hayden DM, Twigg P, Gautam S: Genic microsatellite markers derived from EST sequences of switchgrass (Panicum virgatum L.). Mole Ecol Notes 2006, 1:185-187.

12. Tobias CM, Gautam S, Twigg P, Lindquist E, Pangilinan J, Penning BW, Barry K, McCann MC, Carpita NC, Lazo GR: Comparative genomics in switchgrass using 61585 high-quality expressed sequence tags. The Plant Genome 2008, 1:111-124, (2008)

13. Okada M, Lanzatella C, Saha MC, Bouton J, Wu R, Tobias CM: Complete switchgrass genetic maps reveal subgenome collinearity, preferential pairing, and multilocus interaction. Genetics 2010, 185:745-760.

14. Wang YW, Samuels TD, WU YQ: Development of 1,030 genomic SSR markers in switchgrass. Theor Appl Genet 2011.

15. Missaoui $\mathrm{AM}$, Paterson $\mathrm{AH}$, Bouton $\mathrm{JH}$ : Investigation of genomic organization in switchgrass (Panicum virgatum L.) using DNA markers. Theor Appl Genet 2005, 110:1372-1383.

16. Lu K, Kaeppler SM, Vogel KP, Arumuganathan K, Lee DJ: Nuclear DNA content and chromosome numbers in switchgrass. Great Plains Research 1998, 8:269-80.

17. Church GL: Cytotaxonomic studies in the Gramineae: Spartina, Andropogon, and Panicum.. Am J Bot 1940, 27:263-71.

18. Nielson EL: Analysis of variation in Panicum virgatum. J Agr Res 1944 69:327-53

19. McMillan C, Weiler J: Cytogeography of Panicum virgatum in central North America. Ame J Bot 1959, 46:590-93.

20. Barnett FL, Carver RF: Meiosis and pollen stainability in switchgrass, Panicum virgatum L. Crop Sci 1967, 7:301-304.

21. Riley RD, Vogel KP: Chromosome numbers of released cultivars of switchgrass, indiangrass, big bluestem, and sand bluestem. Crop Sci 1982, 22:1082-1083.

22. Brunken JN, Estes JR: Cytological variation in Panicum virgatum L. The Southwestern Naturalist 1975, 4:379-405.

23. Porter $\mathrm{CL}$ : An analysis of variations between upland and lowland switchgrass, P. virgatum L., in central Oklahoma. Ecology 1966, 47:980-92.

24. Luo MC, Ma Y, You FM, Anderson OD, Kopecký D, Šimková H, Šafář J, Doležel J, Gill B, McGuire PE, Dvorak J: Feasibility of physical map construction from fingerprinted bacterial artificial chromosome libraries of polyploid plant species. BMC Genomics 2010, 11:122.

25. Tuskan GA, DiFazio S, Jansson S, Bohlmann J, Grigoriev I, Hellsten U, Putnam N, Ralph S, Rombauts S, Salamov A, et al: The genome of black cottonwood, Populus trichocarpa (Torr. \& Gray). Science 2006, 313:1596-1604

26. Tobias CM: A genome may reduce your carbon footprint. The Plant Genome 2009, 2:5-8.

27. Wicker T, Schlagenhauf E, Graner A, Close TJ, Keller B, Stein N: 454 sequencing put to the test using the complex genome of barley. BMC Genomics 2006, 7:275.

28. Yamamuro C, Ihara Y, Wu X, Noguchi T, Fujioka S, Takatsuto S, Ashikari M, Kitano $\mathrm{H}$, Matsuoka M: Loss of function of a rice brassinosteroid insensitive1 homolog prevents internode elongation and bending of the lamina joint. Plant Cell 2000, 12:1591-1605.

29. Clouse SD, Langford M, McMorris TC: A brassinosteroid-insensitive mutant in Arabidopsis thaliana exhibits multiple defects in growth and development. Plant Physiol 1996, 111:671-678.

30. Kauschmann A, Jessop A, Koncz C, Szekeres M, Willmitzer L, Altmann T: Genetic evidence for an essential role of brassinosteroids in plant development. Plant J 1996, 9:701-703

31. Li J, Chory J: A putative leucine-rich repeat receptor kinase involved in brassinosteroid signal transduction. Cell 1997, 90:929-938.

32. Ding Y, Johnson MD, Colayco R, Chen YJ, Melnyk J, Schmitt H, Shizuya H: Contig asembly of bacterial artificial chromosome clones through multiplexed fluorescence-labeled fingerprinting. Genomics 1999 56:237-246.

33. Ding $Y$, Johnson MD, Chen WQ, Wong D, Chen YJ, Benson SC, Lam JY, Kim YM, Shizuya H: Five-color-based high-information-content fingerprinting of bacterial artificial chromosome clones using type IIS restriction endonucleases. Genomics 2001, 74:142-154.

34. Luo MC, Thomas C, You FM, Hsiao J, Ouyang S, Buell CR, Malandro M, McGuire PE, Anderson OD, Dvorak J: High-throughput fingerprinting of bacterial artificial chromosomes using the SNaPshot labeling kit and sizing of restriction fragments by capillary electrophoresis. Genomics 2003, 82:378-389.

35. Altschul SF, Gish W, Miller W, Myers EW, Lipman DJ: Basic local alignment search tool. J Mol Biol 1990, 215:403-410.

36. Leitch IJ, Bennett MD: Polyploidy in angiosperms. Trends Plant Sci 1997 2:470-476

37. Otto SP, Whitton J: Polyploid incidence and evolution. Annu Rev Genet 2000, 34:401-437.

38. Wendel JF: Genome evolution in polyploids. Plant Mol Biol 2000, 42:225-249.

39. Saini N, Shultz J, Lightfoot DA: Re-annotation of the physical map of Glycine max for polyploid-like regions by BAC end sequence driven whole genome shotgun read assembly. BMC Genomics 2008, 9:323.

40. van Oeveren J, de Ruiter M, Jesse T, van der Poel H, Tang J, Yalcin F, Janssen A, Volpin H, Stormo KE, Bogden R, van Eijk MJ, Prins M: Sequencebased physical mapping of complex genomes by whole genome profiling. Genome Res 2011, 21:618-625.

41. Luo M, Wing RA: An improved method for plant BAC library construction. In Plant Functional Genomics: Methods and Protocols. Volume 236. Edited by: Grotewold E. Totowa, Humana Press; 2003:3-19.

42. Luo M, Wang $Y H$, Frisch D, Joobeur $T$, Wing RA, Dean RA: Melon bacterial artificial chromosome (BAC) library construction using improved methods and identification of clones linked to the locus conferring resistance to melon Fusarium wilt (Fom-2). Genome 2001, 44:154-162.

43. Luo H, Van Coppenolle B, Seguin M, Boutry M: Mitochondrial DNA polymorphism and phylogenetic relationship in Hevea brasiliensis. Mol Breeding 1995, 1:51-63.

44. Fang GC, Blackmon BP, Henry DC, Staton ME, Saski CA, Hodges SA Tomkins JP, Luo H: Genomic tools development for Aquilegia: Construction of a BAC-based physical map. BMC Genomics 2010, 11:621

45. Schwartz S, Zhang Z, Frazer KA, Smit A, Riemer C, Bouck J, Gibbs R, Hardison R, Miller W: PipMaker - a web server for aligning two genomic DNA sequences. Genome Res 2000, 10:577-586.

46. Frazer KA, Pachter L, Poliakov A, Rubin EM, Dubchak I: VISTA: computational tools for comparative genomics. Nucleic Acids Res 2004, 32 Web Server: W273-9.

47. Brudno M, Do CB, Cooper GM, Kim MF, Davydov E, Green ED, Sidow A, Batzoglou S: NISC comparative sequencing program. LAGAN and multi- 
LAGAN: efficient tools for large-scale multiple alignment of genomic DNA. Genome Res 2003, 13:721-731.

48. Kohany O, Gentles AJ, Hankus L, Jurka J: Annotation, submission and screening of repetitive elements in Repbase: RepbaseSubmitter and Censor. BMC Bioinformatics 2006, 7:474.

doi:10.1186/1471-2164-12-369

Cite this article as: Saski et al: New genomic resources for switchgrass: a BAC library and comparative analysis of homoeologous genomic regions harboring bioenergy traits. BMC Genomics 2011 12:369.

Submit your next manuscript to BioMed Central and take full advantage of:

- Convenient online submission

- Thorough peer review

- No space constraints or color figure charges

- Immediate publication on acceptance

- Inclusion in PubMed, CAS, Scopus and Google Scholar

- Research which is freely available for redistribution

Submit your manuscript at www.biomedcentral.com/submit
() Biomed Central 